\title{
Optimum Polymer Concentration in EOR
}

\author{
Esraa Osama Moussa ${ }^{1}$ and Attia M. Attia ${ }^{1}$ \\ Petroleum Engineering Department, The British University in Egypt, Cairo, Egypt ${ }^{1}$
}

\begin{abstract}
Polymer Flooding is one of the most economic attractive EOR techniques which are used to improve the sweep efficiency, and in turn extract large fraction of the residual oil after primary recovery. The selection of the optimum polymer concentration should be considered as a main step in designing a polymer flooding project since it affects both the technical and economic feasibility of the project. There are several factors such as shearing, temperature, salinity and adsorption influencing the polymer concentration and viscosity required for achieving favorable mobility ratio. Thus, the impact of these factors should be considered while selecting the optimum concentration. The objectives of this research are to investigate the effect of polymer types, concentration, and adsorption and slug sizes on oil recovery at low and extremely high salinity. Rheological behavior of two types of polymer: Xanthan gum and PAM were measured in high salinity high temperature (HSHT). The effect of polymer adsorption was measured to determine the optimum polymer concentration. Results showed that the optimum polymer concentration was $500 \mathrm{ppm}$ based on the relative permeability data and shear rate of $10 \mathrm{~s}^{-1}$.in porous media. In addition, the effects of polymer concentration and slug size on cumulative oil recovery were investigated showing that the recovery factor increases with increasing the polymer concentration with an optimum slug size 0.6 PV. These extensive laboratory tests conducted will help in selecting the optimum polymer slug, concentration at reservoir conditions that will provide the favorable mobility ratio. The economic evaluation of the project based on the simulation study and polymer properties measured in the lab showed that the polymer flooding is economically feasible, since the project earned much higher NPV than water flooding. . A new correlation will be developed to be used to calculate the resistance factor at different shear rates. Finally, The economic feasibility of the selected concentration and slug size are determined.
\end{abstract}

Keywords: Enhanced oil recovery, Polymer, Slug size, Cumulative oil recovery, Adsorption, concentration.

\section{INTRODUCTION}

Chattergi \& Burchardt (1981) explained that the word polymer is derived from two Greek words which mean many parts, while part is a molecule that forms chemical compound. Co- polymer is another term used to describe two different joining polymers. In addition, , Kenneth (1991) stated that polymer flooding is possibly the most common EOR method to be applied due to its simplicity as it's considered an augmented water flood. VargasVasquez (2008) reported that during the process of flooding, HPAM and polysaccharides (Xanthan gum) are the two main types of water soluble polymers used. They are injected into reservoir to form polymer gel when reacting with cross-linking agents. In addition, this polymer gel when reaches the target zones can be used to divert flow and control flow of water in zones of production.

Detling (1944) investigated the effect of adding polymer solution during water flooding process and observed that it resulted in better sweeping efficiency and that was one of the chemical enhanced oil recovery methods.

Caenn et al. (1985) stated that the use of water soluble polymers is considered an extension of water flooding and is one of the most promising enhanced oil recovery techniques. In polymer flooding operations, high molecular weight polymers are used. Furthermore, low concentration polymer solutions can give high viscosity according to results of an experiment, $0.05 \mathrm{wt} \%$ polyacrylamide can give $10 \mathrm{cp}$ viscosity at $12.5 \mathrm{~s}^{-1}$ shear rate, while 0.055 xanthan gum can give the same viscosity at same shear rate. Zhang(2003) reported that the goals of implementing polymer flooding project is to attain the largest contact along the reservoir area to reach the maximum efficiency and to have favorable mobility ratio due to piston-like displacement.

According to Gloria (2014), that mixing polymer with water through the process of water flooding results in a smooth flood and reduces the unfavorable fingering of water.

Moreover, Teyyub (2014) continues to explain that it's preferable to have the mobility ratio less than one in order for the oil to have higher mobility and avoid water breakthrough and minimize the amount of water produced with the oil. Consequently, sweeping efficiency will be much better reducing the fingering effect. Water fingering occurs when the water's mobility is much greater than the oil mobility due to low water viscosity, causing oil to remain attached at rock, while water is allowed to flow which results in water breakthrough. Therefore, polymer flooding is required as its mechanism is based on: Increasing the water viscosity, reducing the mobility ratio and removing water from swept zones when Shah (1977) stated that adding these polymers to the injection water for the following purposes: achieve favorable mobility ratio, sweeping efficiency (overall recovery) to remove oil from 
swept zones and it also has an effect on fractional flow which is a function of reciprocal of mobility ratio Sandiford \& Pye (1964) conducted field and laboratory tests showing conclusive results as increase in recovery factor due to reducing the amount of water produced with the oil. Since then, polymer flooding was announced as an effective enhanced oil recovery technique.

In addition, Terry \& Donald E. (1966) observed that the ultimate oil recovery increased with $10.76 \%$ when a polymer solution of $0.05 \%$ concentration was used as a displacing medium through a core instead of 50,000 ppm brine solution and it was concluded that this improvement was due to a change in the viscosity after adding the polymer. Since it was observed that polymer solutions improved the water flood performance, several polymer flood projects were designed.

Moreover, Mungan(1970) pointed out that the first successful polymer flooding project that was economically worthy took place in china at Daqing field. The recovery factor increased about $20 \%$ after polymer flooding which was considered an ideal outcome

According to Litmann (1988), Polymer flooding is considered one of the most attractive enhanced oil recovery methods for not being risky and having broad range of applications. Also, it has been executed in conventional reservoirs for over than 20 years achieving an increase of (15-20) \% over primary and secondary methods. This method is attained by adding polymers to the injected water to enhance the mobility ratio and sweeping efficiency by increasing its viscosity.

Leonhardt et al.(2015) illustrated that polymer flooding is the most commonly applied EOR technique due to its high success rate, but some limitations and recommendation should be taken into consideration. Under high temperature and salinity the polymer efficiency decreases. Also, the chemical, biological, mechanical degradation are one of the limitations during flooding as they affect the polymer solution's stability.

\section{BACKGROUND THEORY}

\section{Mechanism of Polymer Flooding}

\section{Fractional Flow}

According to Buckley \& levertt (1942), the fractional flow is the ratio of water production rate to the total flow rate as shown in equation 2-2. It can also be expressed in other form as in equation 2-3 for field calculations and increasing the fractional flow indicates high water production.

$$
\begin{gathered}
\mathrm{fW}=\frac{1}{1+\frac{\mathrm{kro} * \mu \mathrm{w}}{\mathrm{krw} * \mu \mathrm{o}}}=\frac{1}{1+\frac{1}{\mathrm{M}}} \quad(\mathrm{Eq} 2-2) \\
\mathrm{fW}=\frac{1+\left(\frac{0.0001127 \mathrm{kk}_{\mathrm{ro}} \mathrm{A}}{\square_{\mathrm{o}} \mathrm{i}_{\mathrm{w}}}\right)\left[\frac{\partial \mathrm{p}_{\mathrm{c}}}{\partial \mathrm{x}}-0.433 \Delta \rho \sin ((\alpha)]\right.}{1+\frac{\mathrm{kro}}{\mathrm{krw}} \square_{\mathrm{W}}}
\end{gathered}
$$

Where $\mathrm{k}$ : absolute permeability, $\mathrm{k}_{\mathrm{ro}}$ : relative permeability to oil, A:area, ? ? $_{0}$ : oil viscosity, $\mathrm{i}_{\mathrm{w}}$ : water injection rate bbl/day, $?_{w}$ : water viscosity, krw: relative permeability to water , $\Delta \rho$ : difference between the densities of the two immiscible fluids , $\alpha$ : dip angle , fw : water cut

Litmann (1989) explained that adding polymer solution has an effect on fractional flow equation which describes the fraction of water flow rate to the total flow rate.it is a function of the mobility ratio as when the mobility ratio decreases, the WOR decreases.

\section{Mobility Ratio:}

Habermann (1960) explained that the mobility ratio is ratio between the mobility of displacing fluid (water) to the mobility of displaced fluid (oil) as shown in equation 2-1

$$
\mathrm{Mr}=\frac{\lambda \mathrm{w}}{\lambda_{0}}=\frac{\left(\frac{\mathrm{kw}}{\mu \mathrm{w}}\right)}{\left(\frac{\mathrm{ko}}{\mu \mathrm{o}}\right)}(\operatorname{Eq} 2-1)
$$

Where M: Mobility ratio, krw: Relative permeability of water, kro: Relative permeability of oil, $\mu \mathrm{o}$ : Viscosity of oil, $\mu \mathrm{w}$ : Viscosity of water

A favorable mobility ratio is achieved when equation 2-1 is less than or equal to one, which means that the displacing fluid is moving slower than the displaced fluid (oil) providing piston like displacement and reducing the fingering effect. Caenn et al. (1985) explained that the main function of the polymers is to control mobility of water an provide favorable mobility ratio by increasing the viscosity of the water and decreasing its mobility. Thus, the mobility ratio is decreased and allow oil to move faster into producing wells.

\section{Polymer Rheology}

Mungan, (1969) illustrated that polymers viscosity is not constant when exposed to any external force or stress and it is affected by temperature, magnitude of force ,nature of solution itself investigsting the relation between shear rates and polymer viscosity. The viscosity was measured at different shear rates ranging from 7-2000 $\mathrm{sec}^{-1}$ and it was observed that the viscosity of polymer solution remained high at low shear rates, while it started to drop when rates increase. Thus, it classiefied as non-newtonian fluid due to the dependance of their viscosity on shear rates.Polymer solutions used in EOR processes are termed as shear thinning due to the decrease in its apparent viscosity at high shear rates. This decrease in viscosity results in molecules alignment with shear to reduce internal friction. Chang, (1978) pointed out that the shear rates are not well defined in the reservoir rock matrix, so it is difficult to predict the behavior of polymer solution in reservoir. Several equations are used to calculate the shear rate in formation.

\section{Effect of salinity on Polymer Rheology}

Moradi (1984) illustrated that at high salinity environments the cations present in dissolved salts causes 


\section{International Advanced Research Journal in Science, Engineering and Technology}

ISO 3297:2007 Certified

Vol. 3, Issue 10, October 2016

the double layer of negative charges around carboxylate group of polymer's back bone to collapse and screen. Thus, the repulsive forces are reduced which results in decreasing the viscosity and poor performance due to the deterioration of the polymer solution. Ryles (1988), investigated the effect of $\mathrm{Ca}^{2+}$ ion presence at concentration above $200 \mathrm{ppm}$ and observed that the polymer lost one half of its viscosity at initial conditions. Also $\mathrm{Mg}^{2+}$ gave similar effect, but some how less than calcuim ions.In addition, Litmann, (1989) stated that there is an inversely proportional relation between the salt concentration and viscofying efficiency of a polymer as for every $10 \%$ increase in salt concentration, the viscosity in decreased by $10 \%$.

Algharaib \& R. Gharbi (2011) conducted a study for several reservoirs where the water was too saline and concluded that polymer flooding is not preferred when dissolved salt content is above 100,000 ppm. This study was applied using core samples saturated with oil of $10 \mathrm{cp}$ and brine of high salt content at temperature of 176 degrees Fahrenheit and injected polymer of $15 \mathrm{cp}$ dissolved in 30,000 ppm salinity water. The oil recovery was compared to a water flood and it gave same recovery, which reflects that the polymer failed to increase recovery as the viscosity of polymer degraded because it's in direct contact with high salinity water.

\section{Effect of Temperature on Polymer Rheology}

Knight (1973) pointed out that high temperature may result in polymer degradation in two ways after studying the effect of temperature on polymer's stability and observed that at temperatures from $(120-150)$ degree celsuis which is equivalent to (250-300) Fahrenhiet polymers may lose their viscosity permanently.

Additionally, high temperature accelerates oxgyen freeradical reactions, which causes the polymer to damage rapidly. Also, Knight (1973) investigated the rate of polymer degradation due to presence of oxgyen at three different temperatures 140, 120, 73 degree Fahrnenhiet and concluded that at elevated temperature, polymer deterioration takes place faster, but the total loss of viscosity is the same at the three temperatures. furthermore, Cannella (1988) observed the impact of elevated temperatures on flow behaviour of polymer solution (xanthan gum) and reported that the polymer started to behave as newtonian fluid at 80 degrees celsuis at low shear rate.

\section{Effect of Concentration on Polymer Rheology}

Wang \&caudle (1970) stated that for an efficient oil recovery, a concentrated polymer slug is required and explained that increasing the polymer concentration reduces the voulme of the required slug. An experiment was conducted using $0.4 \mathrm{pv}$ slug size to attain $60 \mathrm{cp}$ viscosity and it was concluded that the viscosity of the polymer solution is a function of the concentration.Ferry J.D( 1980) Pointed out that increasing the polymer concentration causes the molecules to interact with each other (hydrodynamic interaction) which is a long range effect, then formas actual contacts, aggregates and networks. Yang et al.( 2004) investigated the effect of increasing HPAM \& Xanthan gum polymer's concentration on increasing the viscosity, thus improving the oil recovery. An experiment was conducted using HPAM of $(200,600,1500,2000,2500)$ ppm and Xanthan gum of $(840,2250,3440,4790) \mathrm{ppm}$. Results showed that the viscosity increases with increasing the concentration for the two types of polymers. Thus the recovery was increased with $20 \%$ of OIIP

\section{Effect of Concentration on Polymer Adsorption}

According to Sarem(1970), as the polymer solution flows through porous media, its large molecules will adhere to the rock surface as it will not be able to pass through narrow pores. This behaviour is desired to a certain limit as when polymer molecules attatch to the surface, they stretch out and plug the path of water, thus its mobility is lowered. However, it is not favorable for polymer to adsorb permanentlor slowly as this may result in excessive loss of the polymer or small flow resistance which will affect the profitability of polymer flooding project.

Omar (1983) investigated the effect of adsorption on polymer losses and concluded that when polymer molecules adsorb on rock surface, the concentration of the solution leaving the pores is lower than the concentration of the initial polymer solution injected. This reduction in polymer concentration can be used as a measure of the adsorption. Thus polymer adsorption results in an increase in the polymer resistance to flow and loss of polymer.

\section{Methodology}

In this study, several factors affecting the polymer rheology will be investigated as salinity, temperature and concentration for two different types of polymer (X.G, PAM) on order to select the optimum polymer concentration at shear rate in porous media and slug size. The effect of adsorption will be investigated in order to consider the losses of polymer and Use the selected concentration and slug size in polymer flooding as secondary and tertiary recovery.

\section{Experimental Work}

The experimental work in this research is divided into different stages to select the optimum polymer concentration, so the polymer solution is prepared first to study its rheological behavior and use the optimum concentration selected in core flooding test to observe its effect on increasing the oil recovery.

\section{RESULTS AND DISCUSSION}

\section{Selecting optimum polymer concentration}

Before starting polymer flooding, the mobility ratio required must be estimated to select the optimum polymer concentration that will achieve the desired mobility ratio at the shear rate in the formation. It must be selected based on the formation salinity which is $3.5 \%$ NACL since the 


\section{International Advanced Research Journal in Science, Engineering and Technology}

ISO 3297:2007 Certified

Vol. 3, Issue 10, October 2016

core is saturated with 35000 ppm brine solution, kro, krw and oil viscosity (cp). To achieve mobility ratio smaller than or equal to one. since wever et al.(2011) and Larsen (2014) mentioned that the shear rate in the porous media is estimated to be $10 \mathrm{~s}^{-1}$, it will be used in selecting the optimum concentration, with known Kro was , Krw , oil viscosity at room temperature, so according to the mobility ration equation below:

$$
\frac{\mathrm{krw}}{\mathrm{kro}} \times \frac{\square_{0}}{\square_{\mathrm{w}}}<\text { or }=\text { one }
$$

Then the required $?_{\mathrm{w}}$ to achieve the desired mobility ratio is $4.3 \mathrm{cp}$, so the optimum concentration will be selected from the following figure which shows the relation between the shear rate and polymer viscosity at different salinities (rheological behavior):



Figure 1 optimum polymer concentration at $3.5 \%$ salinity

This figure (1) shows the relation between shear rate and viscosity for different polymer concentrations at $3.5 \%$ salinity and the equation for the curve $3.5 \%$ NACL that will be used in choosing the polymer concentration at $10 \mathrm{~s}^{-1}$. According to the figure the polymer concentration that will give the required viscosity $(4.3 \mathrm{cp})$ at the established conditions is 500 ppm of XANTHAN GUM. Thus, the optimum polymer concentration that will be used in polymer flooding under the current conditions (kro, krw, oil viscosity) to attain the desired mobility ratio for this case is $500 \mathrm{ppm}$. However, the effect of adsorption should be taken into consideration while selecting the polymer concentration as some polymer is lost due to adhesion on rock surface, so the amount of polymer lost can be estimated and considered when preparing the polymer solution with the selected concentration to be added. The adsorption for $500 \mathrm{ppm}$ was estimated to be 52 $\mu \mathrm{g} / \mathrm{cc}$ and the reduction concentration due to adsorption is $55 \mathrm{ppm}$, so $555 \mathrm{ppm}$ concentration is prepared to give 500 ppm after adsorption.
Polymer Adsorption Effect Polymer's Viscosity at different concentrations

The effect of adsorption on polymer's viscosity was investigated by measuring the viscosity of the solution at different shear rates $(30,60,100,300,600)$ before and after injection of $16 \mathrm{PV}$ of different polymer concentrations 500,1000, 1500, 2000 ppm dissolved in $3.5 \%$ NACL

These figures(2), (3), (4), (5) shows the relation between the shear rate and viscosity before and after Polymer injection of $16 \mathrm{pv}$ of polymer solution through the core to investigate the effect of adsorption on polymer's viscosity at different shear rates for different polymer concentrations $(500,1000,1500,2000) \mathrm{ppm}$. It is observed that the measured viscosity of the polymer solution after injection is reduced due to loss of some polymer molecules that adheres on the rock surface which results in reduction in both polymer solution's concentration and viscosity. 
International Advanced Research Journal in Science, Engineering and Technology

ISO 3297:2007 Certified

Vol. 3, Issue 10, October 2016

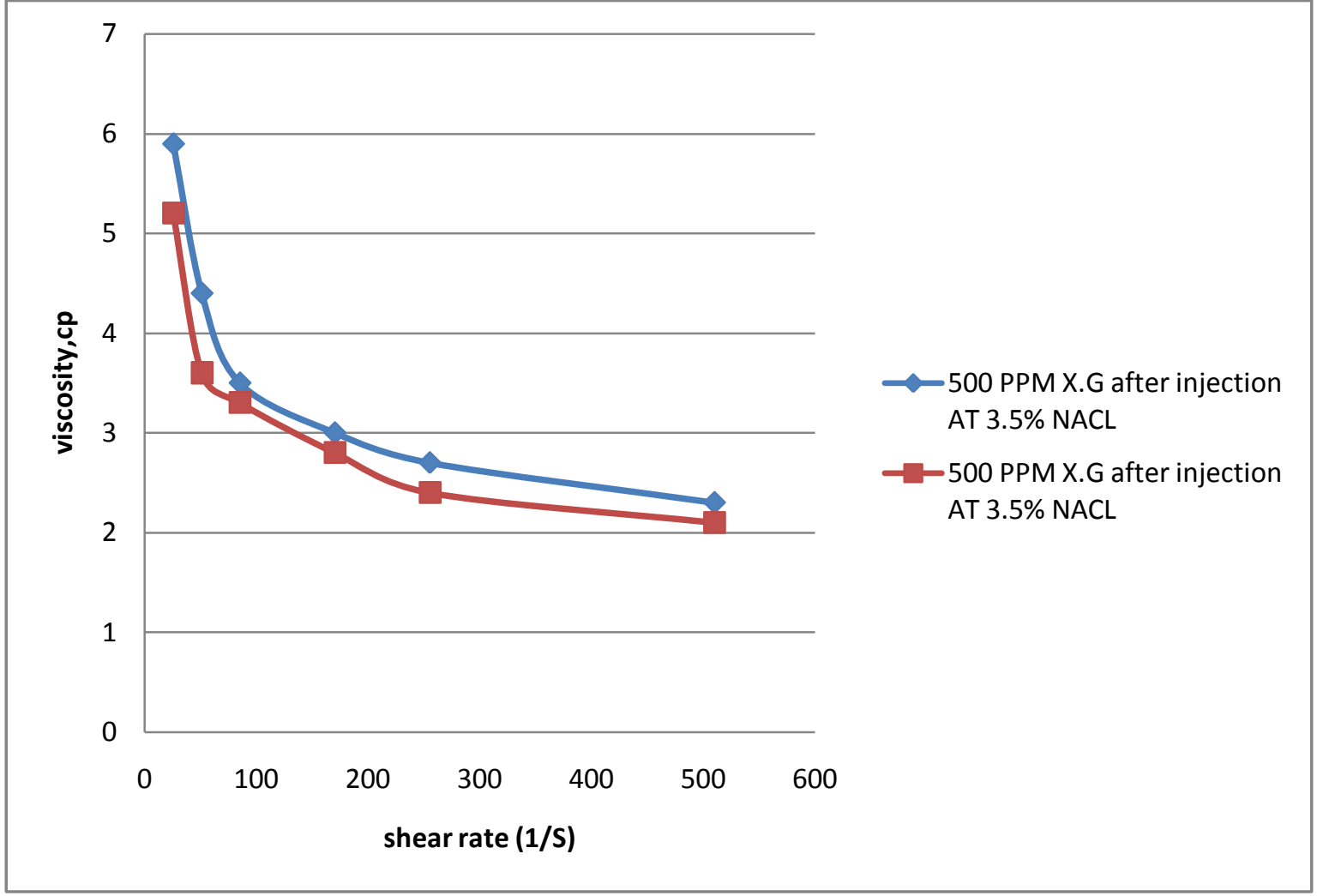

Figure 2 Effect of Adsorption on Polymer Viscosity for 500 ppm X.G

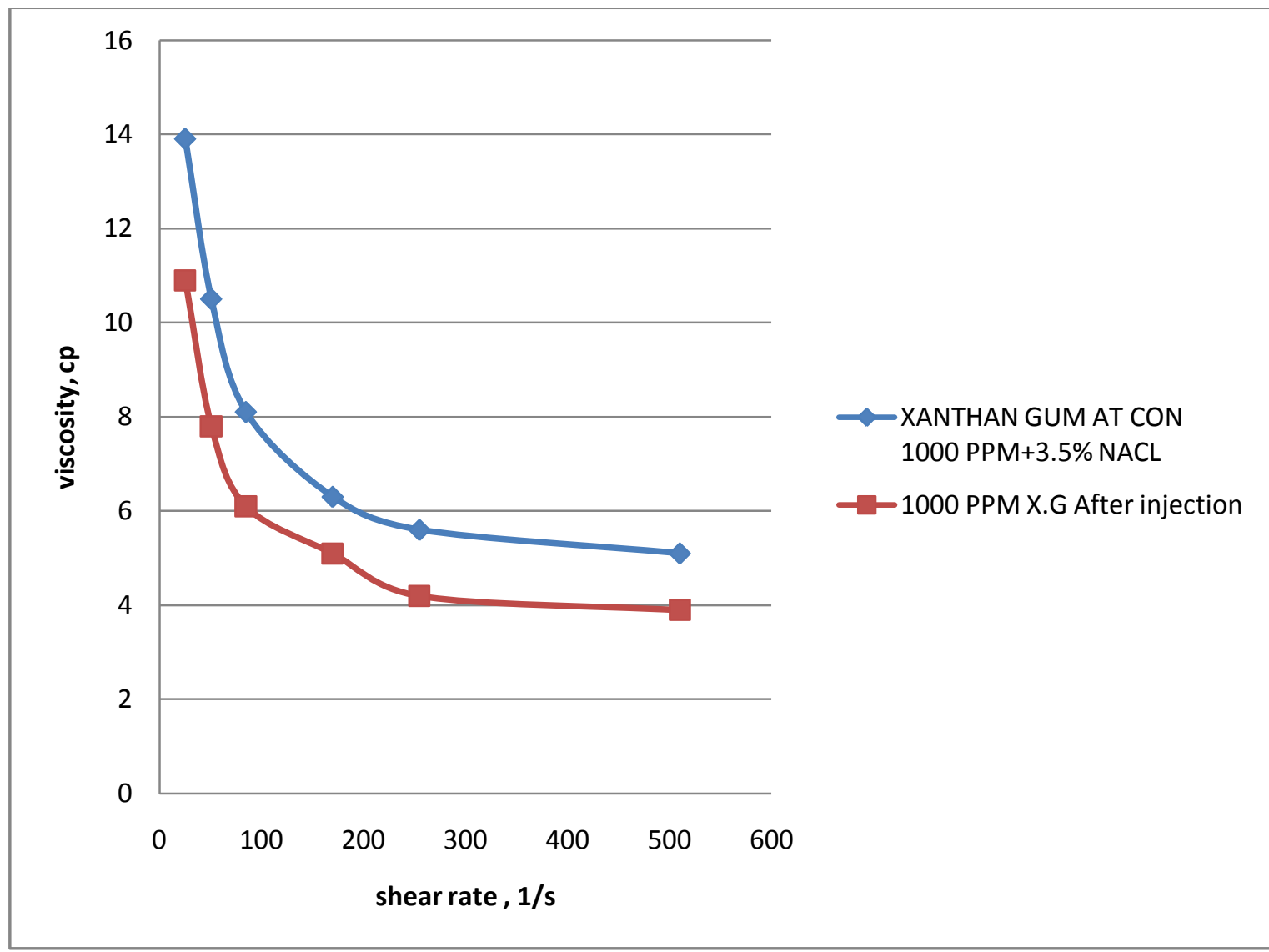

Figure 3 Effect of Adsorption on Polymer Viscosity for 1000 ppm X.G 


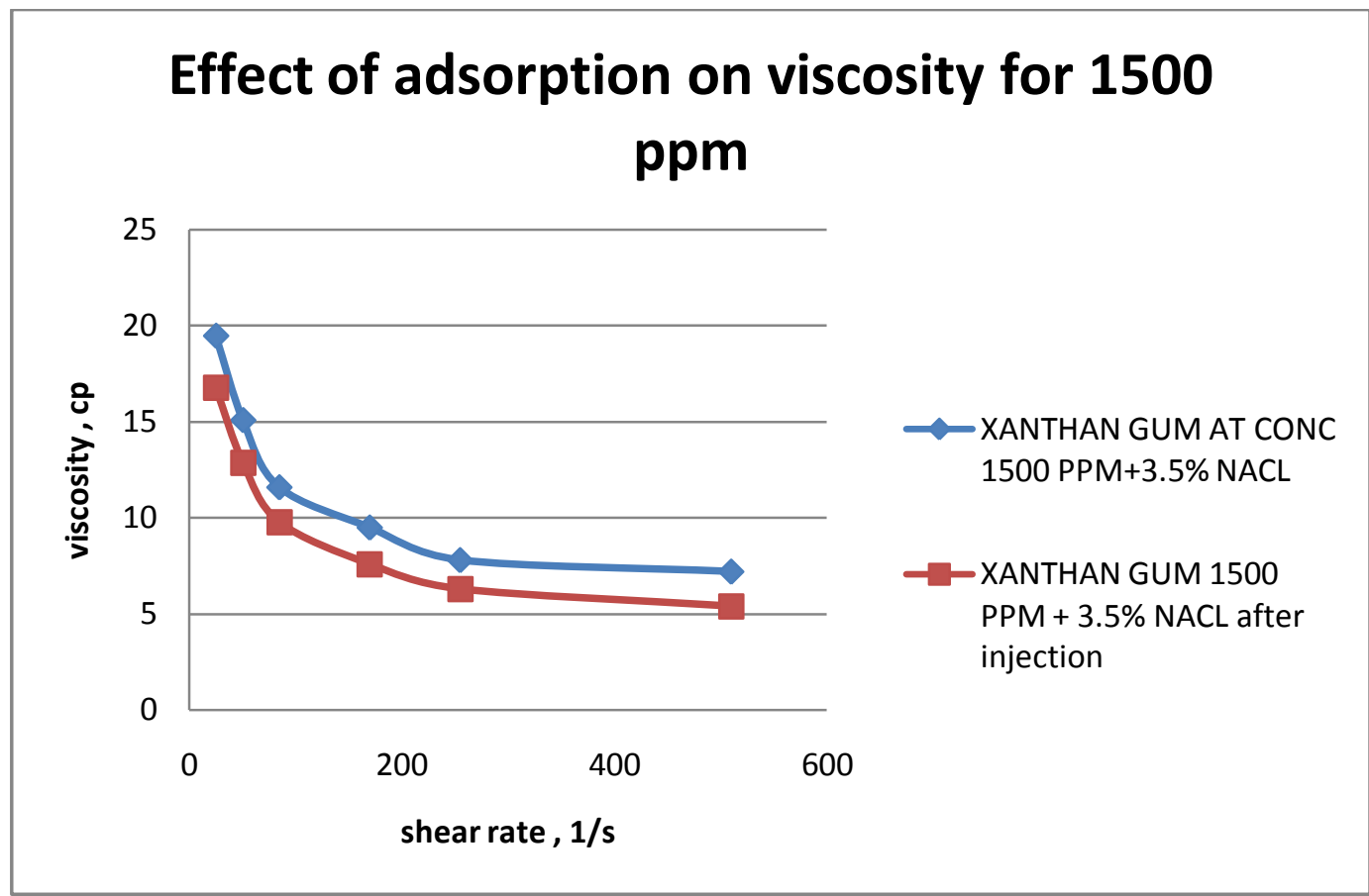

Figure 3 Effect of Adsorption on Polymer Viscosity for 1500 ppm X.G

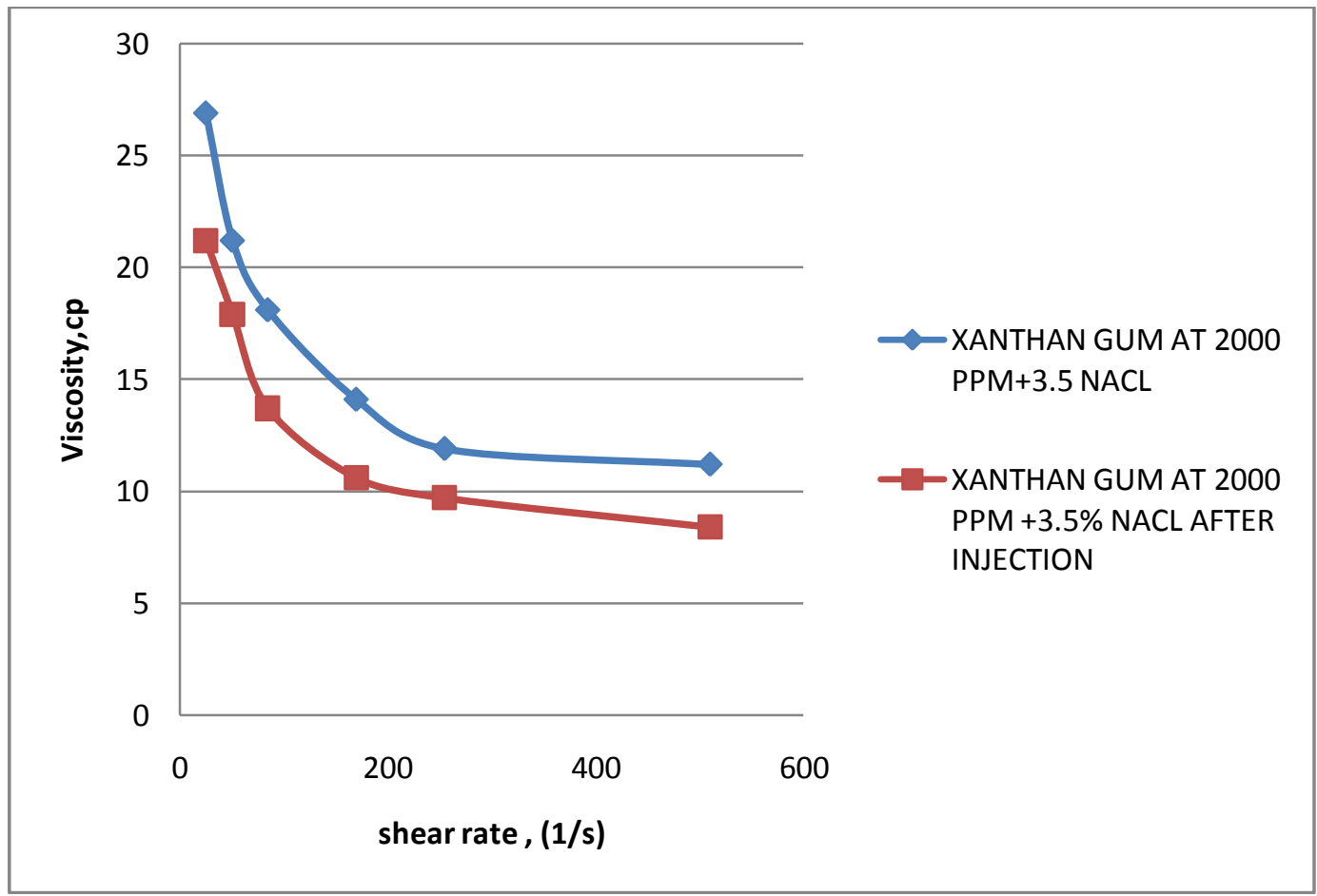

Figure 4 Effect of Adsorption on Polymer Viscosity for 2000 ppm X.G

for $500 \mathrm{ppm}$ the viscosity was reduced from 5.9 to $5.2 \mathrm{cp}$ Huang \& K.S. Sorbie (1992) who stated that as the at $30 \mathrm{1} / \mathrm{s}$ shear rate and further reduction was observed at polymer adsorbes on rock surface the apparent viscosity higher shear rates, while at $1000,1500,2000 \mathrm{ppm}$ the and the non-newtonian behaviour decreases as it passes viscosity was decreased from $13.9,19.5,26.9 \mathrm{cp}$ to 10.9 , through porous media. This is a result of the reduction in $16.8,21.2 \mathrm{cp}$ at $30 \mathrm{1} / \mathrm{s}$ respectively after flowing through concentration. Thus , polymer adsorption results in the core which is about $16-20 \%$ reduction in the original reduction of both the concentration of the solution and viscosity and hence less non-Newtonian behavior. This is hence the viscosity for all concentrations and at different similar to what was mentioned in the literature review by shear rates. 


\section{Effect Of Polymer's Concentration On Adsorption}

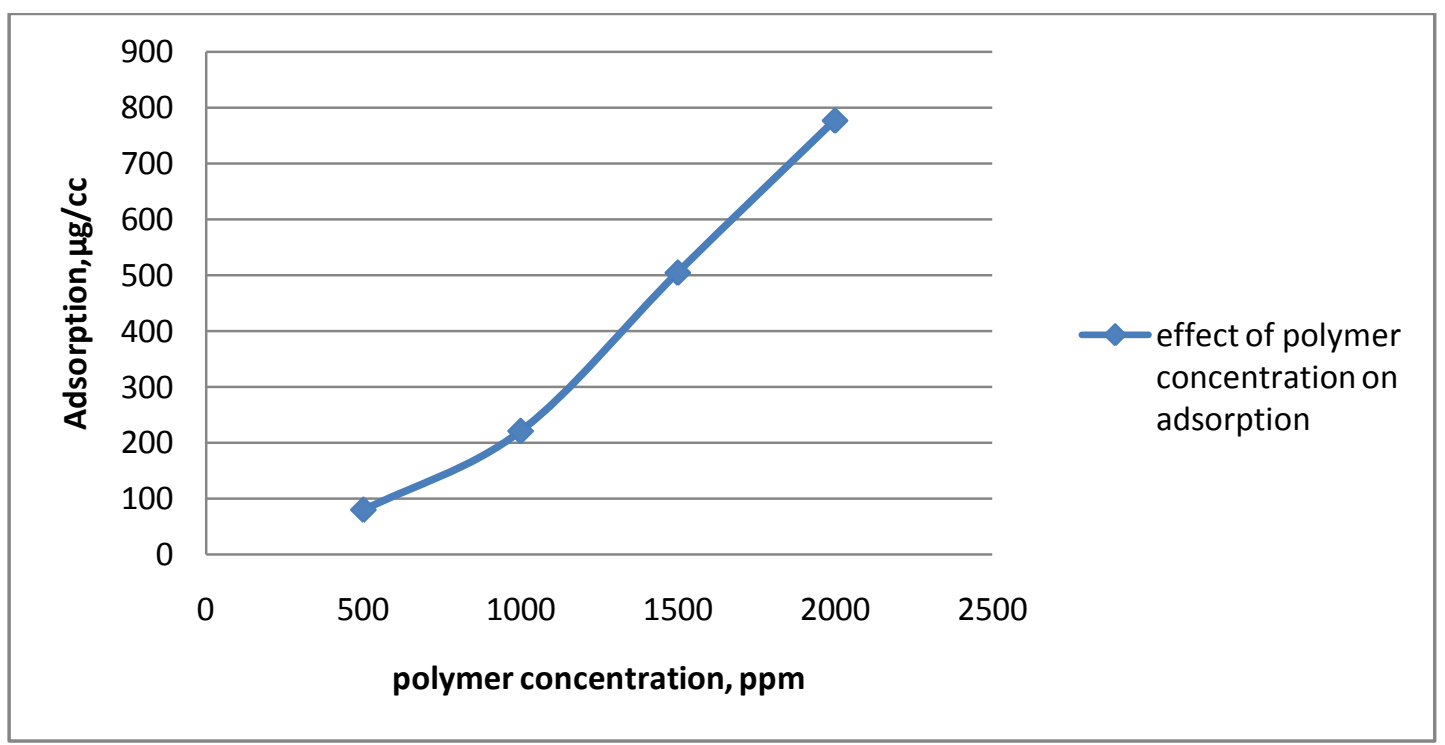

Figure 6 Effect of Polymer Concentration on Adsorption

Figure (6) shows the relation between the polymer solution's concentration in ppm and adsorption for different polymer concentrations 500,1000,1500, $2000 \mathrm{ppm}$. it is observed that with increasing the polymer concentration , more polymer molecules adsorb on the rock surface increasing the value of adsorption which indicates reduction in polymer concentration that should be taken into consideration as mentioned in the literature review by Omar (1983) who investigated the effect of adsorption on polymer losses and concluded that when polymer molecules adsorb on rock surface, the concentration of the solution leaving the pores is lower than the concentration of the initial polymer solution injected. Furthermore, the adsorption increases with increasing the concentration as mentioned in the literature review by Zhang \& Seright (2013) who conducted an experiment using polymer solutions with various concentrations (10-6,000) ppm and results showed that polymer adsorption increased at higher concentrations.

500 ppm polymer flooding secondary recovery

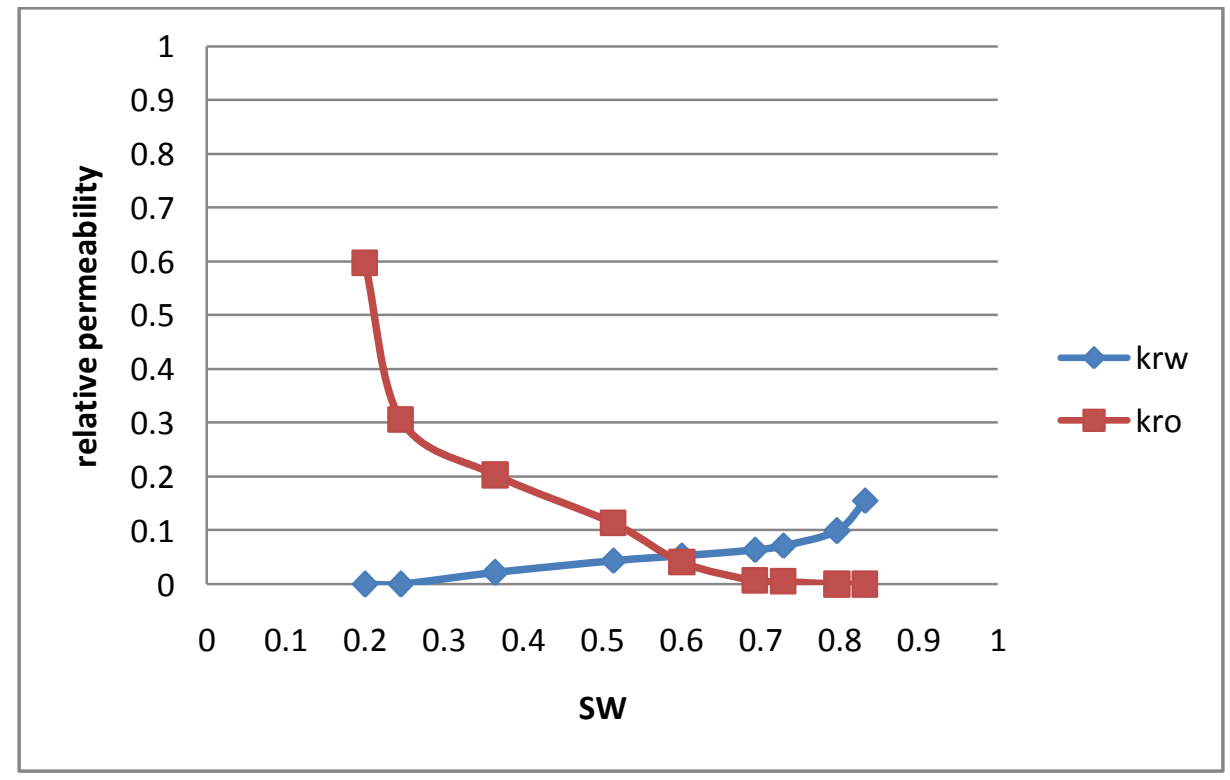

Figure 7 Relative Permeability Saturation curve for 500 ppm

This figure (7) shows the relation between the relative between the kro and krw is above 50 , the relative permeability for oil (kro), water (krw) and water permeability for oil decreases with increasing the water saturation for continuous polymer flooding. It is observed saturation, but yet it is still higher than the relative that the rock is strongly water wet since the intersection permeability to oil in case of water flooding. While, the 
Vol. 3, Issue 10, October 2016

relative permeability to water increases with increasing the relative permeability to water is lower compared to that in water saturation, but in case of polymer flooding, the water flooding.

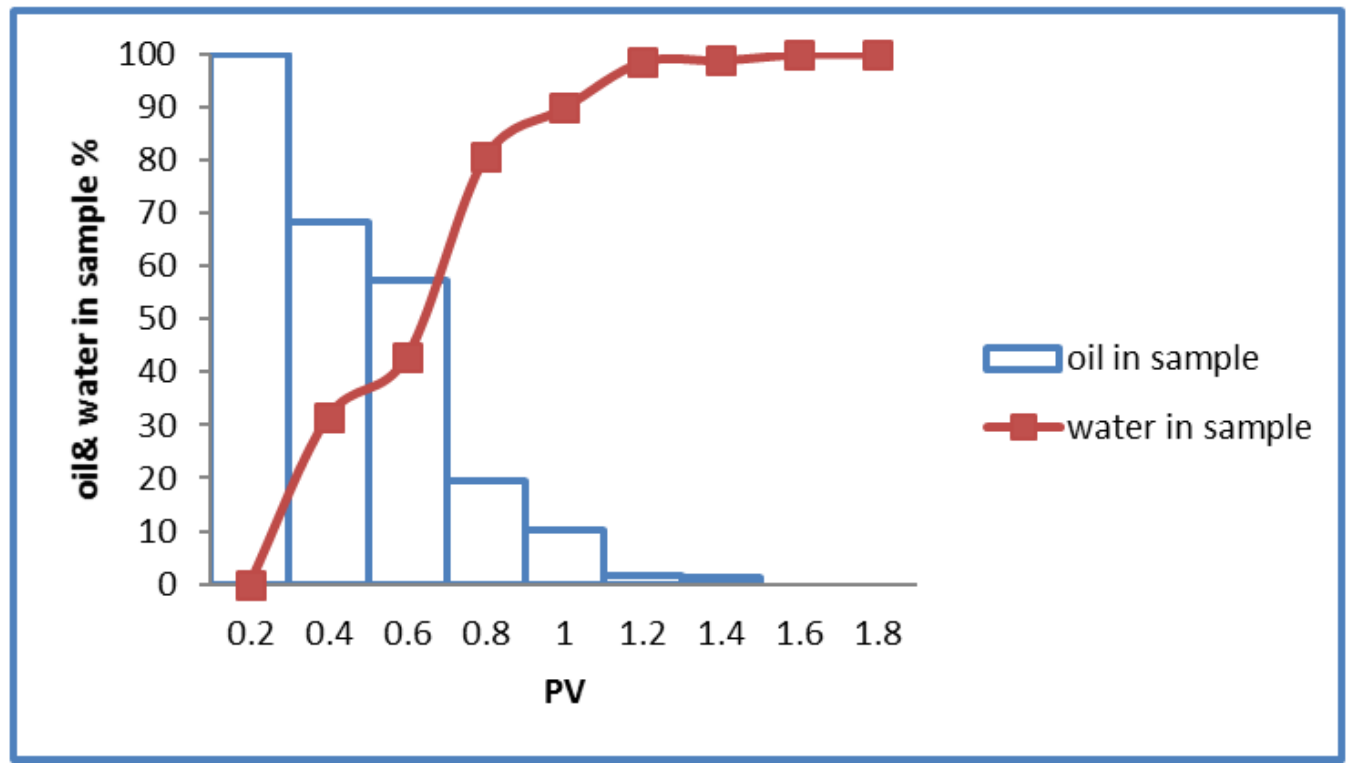

Figure (8) oil and water in sample

This figure (8) shows the relation between the pore It is observed that the volume of oil in sample decreases volume injected and the percent of oil volume in sample, gradually from $100 \%$ until it reaches $0 \%$ while the volume percent of water in sample to the total volume (oil and of water in the sample increases gradually from $0 \%$ to water). $100 \%$

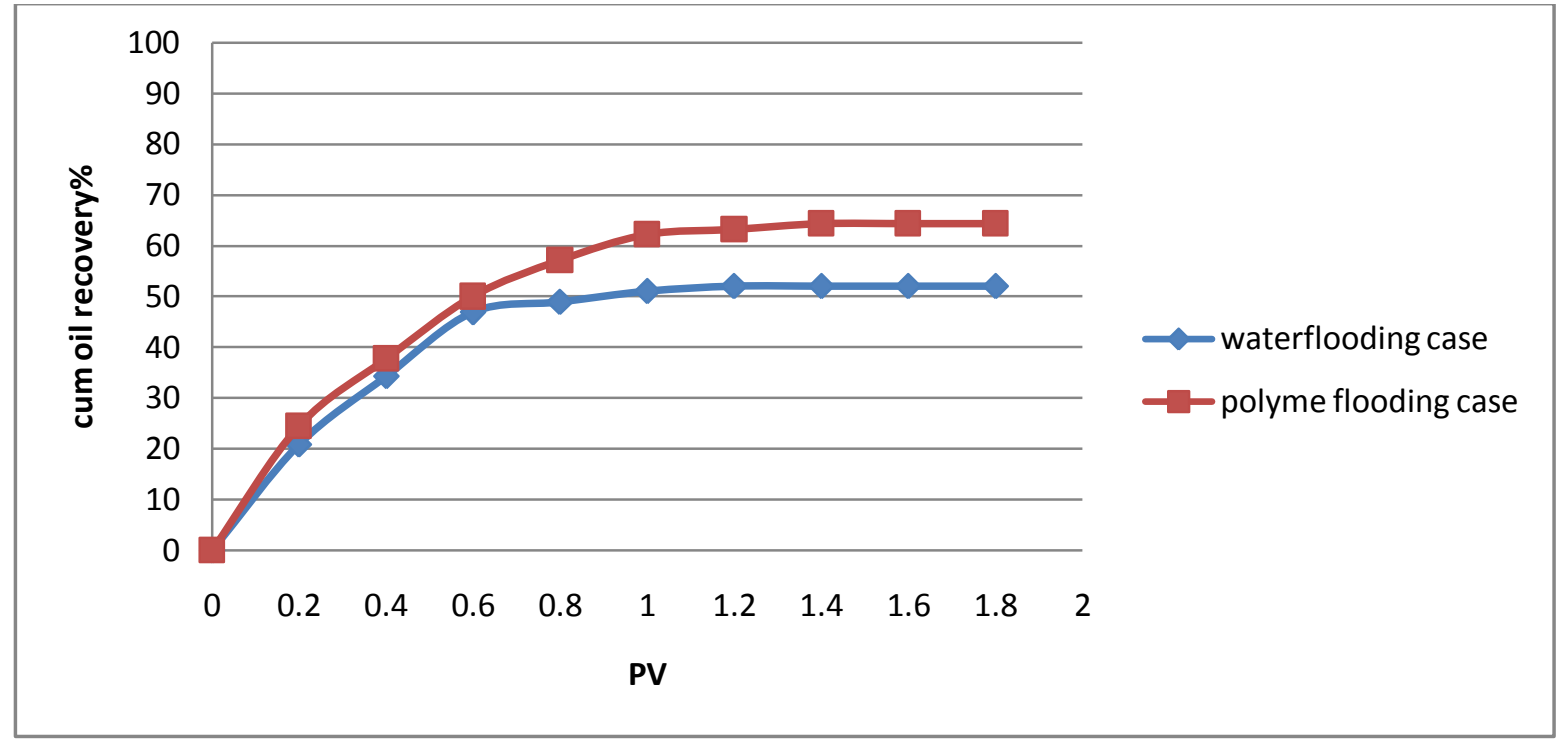

Figure 9 cumulative oil recovery in polymer flooding and water flooding

This figure (9) shows the relation between the pore efficiency in case of polymer flooding and reduction in volume injected and the cumulative oil recovery water cut as the oil moves faster than the water as a result percentage for continuous polymer flooding, the oil of adding polymer which increased the viscosity of the recovery percentage increases with increasing the pore water and lowered its mobility providing favorable volume injected till reaching the maximum recovery and mobility ratio. Recovery was 52\% as shown in the figure. then becomes constant. The maximum oil recovery This is due to better sweep efficiency in case of polymer achieved with $500 \mathrm{ppm}$ continuous polymer flooding was flooding and reduction in water cut as the oil moves faster $64.28 \%$, which represents an increase $12.2 \%$ over the than the water as a result of adding polymer which water flooding at which the maximum oil recovery was increased the viscosity of the water and lowered its $52 \%$ as shown in the figure. This is due to better sweep mobility providing favorable mobility ratio. 
Vol. 3, Issue 10, October 2016



Figure 10 Fractional Flow Curve For 500 ppm Polymer Flooding And Water Flooding

This figure (10) shows the relation between the fractional For water flooding the SW avg was 0.46 which gives flow (water cut) and water saturation for both water displacement efficiency $40 \%$, while for polymer flooding flooding and polymer flooding and it is observed that in the $\mathrm{SW}$ avg increased to 0.68 providing better polymer flooding the curve is shifted to the right which displacement efficiency of $64 \%$, which refers to better indicates more water saturation (higher SW average) at the sweep efficiency due to reduction in water mobility breakthrough point, thus the residual oil is less in case of providing piston like displacement.

polymer flooding. Also, the displacement efficiency was calculated for the water and polymer flooding by drawing a tangent line for each curve as shown above and get the avg water saturation at $\mathrm{fw}=1$ to substitute in the following equation:

Effect of polymer slug size on oil recovery

The effect of increasing the slug size on oil recovery was investigated for polymer X.G Of 500 ppm concentration in order to select the optimum slug size. Different polymer slug sizes were injected $(0.2,0.4,0.6,0.8)$ followed by $\mathrm{ED}=\frac{\text { SWavg }- \text { swi }}{1-\text { swi }}$ brine of 3.5\% NACL till 1.8 PV to study its effect on cumulative oil recovery and select the optimum slug size

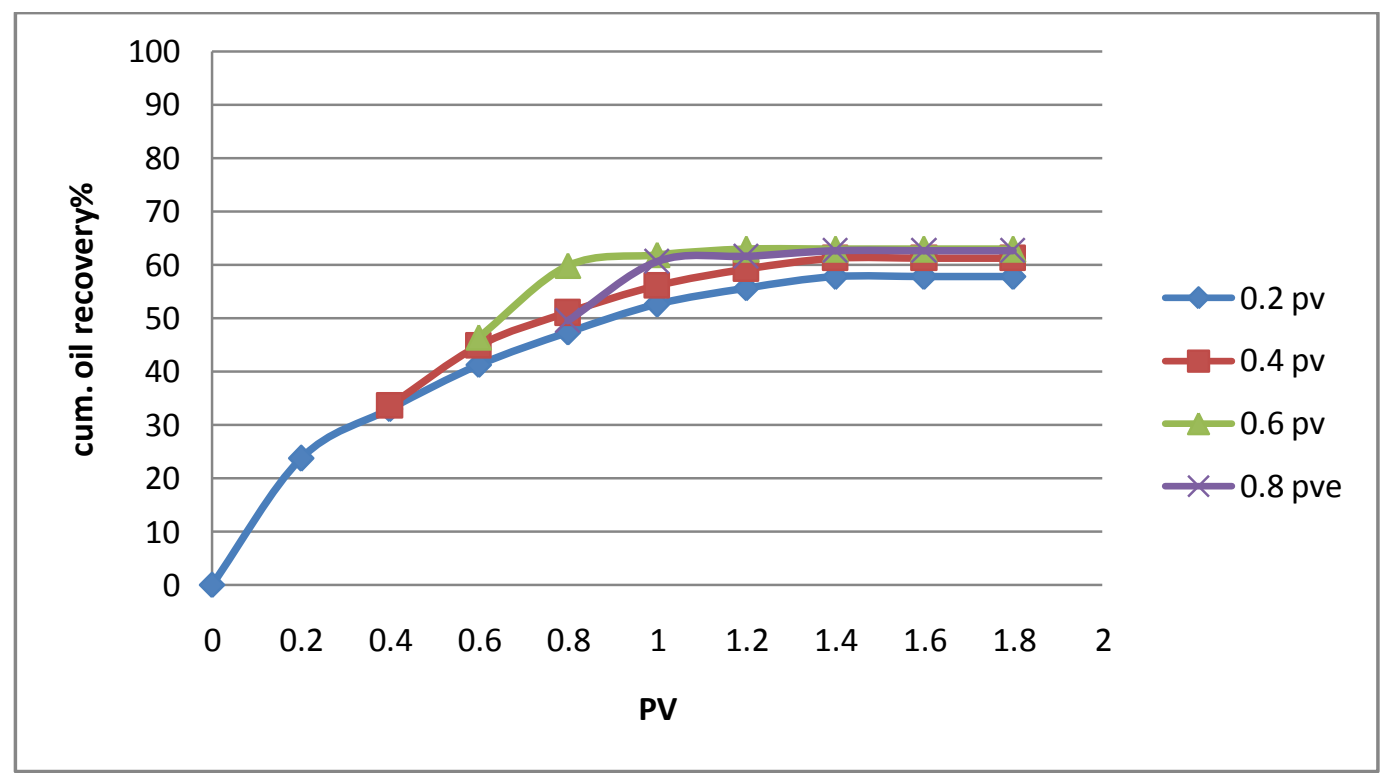

Figure 11 Effect of slug size on cumulative oil Recovery

This figure (11) shows the relation between the pore observed that with increasing the slug size from 0.2 to 0.4 volume injected (PV) and cumulative oil recovered for the cumulative oil recovery increased from $57.7 \%$ to different slug sizes of polymer $0.2,0.4,0.6,0.8 \mathrm{PV}$. It is $61.2 \%$, while the cumulative oil recovery increased from 
$61.2 \%$ to $62.8 \%$ as the slug size increased from 0.4 to 0.6 pv. At slug size of $0.8 \mathrm{pv}$ the cumulative oil recovery was

\section{Tertiary Recovery}

The optimum polymer concentration (500 ppm) and slug size $(0.6 \mathrm{PV})$ that were selected will be used in tertiary
$62.6 \%$ which is somehow close to the recovery for $0.6 \mathrm{PV}$. Thus, the optimum slug size here is $0.6 \mathrm{PV}$.

recovery after water flooding (secondary recovery) to determine the incremental oil that can be produced using polymer flooding as an EOR technique.

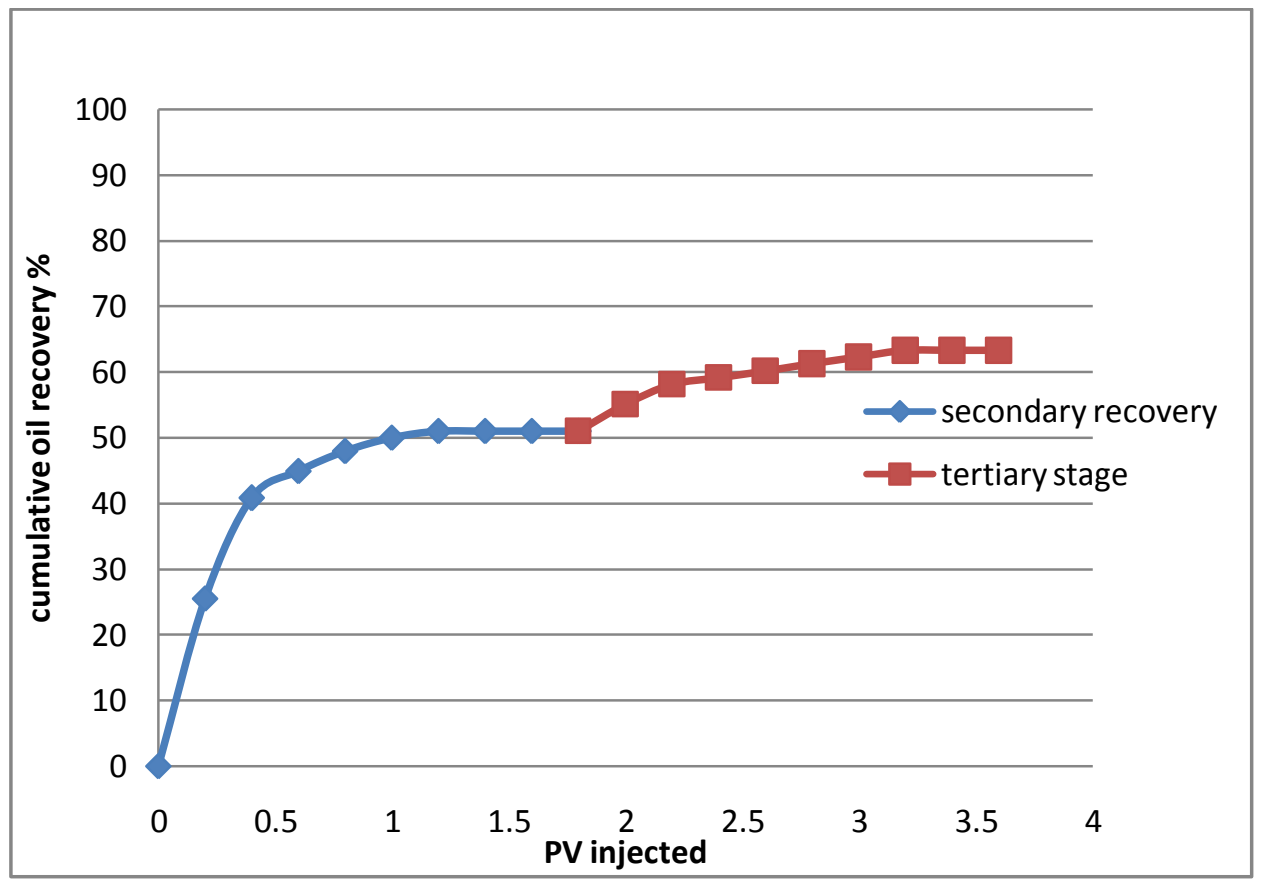

Figure 12 cum oil recovery vs Pv injected in Tertiary stage

This figure (12) shows the relation between the pore volume injected (pv) and cumulative oil recovery $\%$ in tertiary stage. It is divided into two regions as shown, the first trend is the cumulative oil recovery $\%$ for water flooding that is $51 \%$, while the second is the cumulative oil recovery $\%$ for tertiary stage using polymer flooding increased to $63 \%$. This indicates that the incremental oil is $12 \%$ over secondary recovery, which reflects the technical feasibility of polymer flooding as an EOR technique as mentioned by Mungan (1970) who conducted similar experimental work resulting in incremental oil recovery of $20 \%$.

\section{CONCLUSION}

- The viscosity of the two types of polymer solution increases with increasing the concentration from 500 ,1000,1500,2000 ppm, and PAM gives higher viscosity than Xanthan gum of the same concentration at low salinities (0\%,3.5\%,5\% NACL) and room temperature $25^{\circ} \mathrm{C}$, while it starts to lose its Viscofying power at high shear rates $(300,600) \mathrm{s}^{-1}$, due to shear thinning effect. Also, the effect of high salinity of $10 \%, 20 \%$ NACL and high temperature of $75^{\circ} \mathrm{C} \& 100^{\circ} \mathrm{C}$ on viscosity reduction was very significant for the two types, but Xanthan gum is more resistant to shear degradation and its viscosity is greater than PAM at harsh conditions.
- The optimum polymer (Xanthan gum) concentration that will provide favorable mobility ratio was selected as $500 \mathrm{ppm}$ based on the relative permeability data obtained from water flooding, crude oil properties (viscosity) and shear rate in the porous media which is estimated $10 \mathrm{~s}^{-1}$

- The amount of polymer adsorbed on the rock increased with increasing the concentration as $2000 \mathrm{ppm}$ of polymer give the highest adsorption of $442 \mu \mathrm{g} / \mathrm{g}$ while for $500 \mathrm{ppm} 52 \mu \mathrm{g} / \mathrm{g}$. furthermore, adsorption results in loss of the polymer concentration which causes reduction in the viscosity of the solution.

- The optimum slug size that will provide the highest oil recovery is 0.6 PVas with increasing the slug size from 0.2 to 0.4 the cumulative oil recovery increased from $57.7 \%$ to $61.2 \%$, while the cumulative oil recovery increased from $61.2 \%$ to $62.8 \%$ as the slug size increased from 0.4 to $0.6 \mathrm{PV}$. At slug size of $0.8 \mathrm{PV}$ the cumulative oil recovery was $62.6 \%$ which is somehow close to the recovery for $0.6 \mathrm{PV}$. Thus, the optimum slug size is $0.6 \mathrm{PV}$.

- Furthermore, the effect of polymer on fractional flow curve is significant, since there was a reduction in the water cut after using 500 ppm of X.G and better displacement efficiency was achieved. The displacement efficiency increased from $40 \%$ to $64 \%$ and the SW avg at breakthrough from 46 to 68 . 


\section{International Advanced Research Journal in Science, Engineering and Technology}

\section{ISO 3297:2007 Certified}

Vol. 3, Issue 10, October 2016

- The cumulative oil recovered by waterflooding is $52.2 \%$, while the optimum polymer concentration and slug size used in oil displacement in both secondary and tertiary recovery resulted in incremental oil recovery $9.5 \%$ due to polymer flooding as a secondary recovery method as the recovery is $62 \%$ and in tertiary recovery $11 \%$ of IOIP was recovered over water flooding since the cumulative oil recovery is $63.5 \%$. This reflects the efficiency of polymer flooding as an EOR method in field applications, since it improves the sweep efficiency and successively increases the oil recovery.

\section{ACKNOWLEDGMENTS}

This work was supported by the British University in Egypt- Petroleum Engineering and Gas technology Department.

\section{REFERENCES}

[1] Caenn, R., Burneit, \& chilingauruan. (1985), polymer flooding. In E. Donaldson, \& Donaldson (Ed.), Enhanced oil recovery II processes and operations (Vol. 17 B, pp. 157-168). New york: ELseiver.

[2] Detling. (1944). Journal of Petroleum Technology.

[3] Habermann. (1960). The Efficiency of Miscible Displacement. petroleum transactions, 263-265.

[4] Knight, B. (1973, May). Reservoir stability of polymer solutions. Journal of Petroleum Technology, 25(05), 618 - 626.

[5] Litmann, W. (1988). Polymer Flooding. Amesterdam: Elseiver

[6] Lei, M., Zhu, Y., \& Zhuoyan, Z. (2015). Development and Performance of Salt-Resistant Polymers for Chemical Flooding. SPE Middle East Oil \& Gas Show and Conference, 8-11 March,
Manama, Bahrain (pp. 3-4). TEXAS: Society of Petroleum Engineers

[7] Moradi, H. (2011). Experimental investigation of polymer flow through water- and oil-wet porous media. Retrieved from open research archive: http://idtjeneste.nb.no/URN:NBN:nobibsys_brage_ 21632

[8] Mungan, N. (1970). Water Flooding With Polymer Solutions. Society of petroleum engineers Journal, 3-8

[9] Omar, A. (1983). Effect of Polymer Adsorption on Mobility Ratio. Middle East Oil Technical Conference and Exhibition, 14-17 March, Manama, Bahrain (pp. 509-511). Buhrain: society of petroleum engineers.

[10] Pye, D. (1964). Improved Secondary Recovery by Control of Water Mobility. Journal of Petroleum Technology, 911.

[11] Sandiford, B. (1964). Laboratory and Field studies of WaterFloods Using Polymer Solutions to Increase Oil Recoveries. Journal of petroleum Technology, 917.

[12] Sarem, A. (1970). On the Theory of Polymer Solution Flooding Process. Fall Meeting of the Society of Petroleum Engineers of AIME, 4-7 October, Houston, Texas (pp. 2-5). TEXAS: society of petroleum engineers.

[13] Shah, D. (1977). Improved oil Recovery by Surfactant and Polymer Flooding. New York: Academic Press INC.

[14] S.E, B., \& Leverett, M. (1942). Mechanism Of Fluid Displacment in Sands. (pp. 107-116). Texas: AIME.

[15] Sorbie, K. S. (1991). Polymer Improved oil Recovery. New York: Blackie and Son Ltd.

[16] Terry, D. C., \& Donald E. , M. (1966). The Effect of Polymer Additives on Oil Recovery In Conventional Waterflooding. SPE Four Corners Regional Meeting, 9-10 September, Farmington, New Mexico. TEXAS: Society Of Petroleum Engineers.

[17] Wang, G., \& Caudle, B. (1970). Effects of Polymer Concentrations, Slug Size And Permeability Stratification in Viscous Waterfloods. Fall Meeting of the Society of Petroleum Engineers of AIME, 4-7 October, Houston, Texas (pp. 3-4). TEXAS: Society of Petroleum Engineers.

[18] Zhang, G., \& Seright, R. (2003). Effect of Concentration on HPAM Retention in Porous Media. SPE Annual Technical Conference and Exhibition, 30 September-2 October, New Orleans, Louisiana, USA (pp. 3-8). TEXAS: society of petroleum engineers.

\section{Appendix}

\section{Effect of polymer concentration}




International Advanced Research Journal in Science, Engineering and Technology ISO 3297:2007 Certified

Vol. 3, Issue 10, October 2016
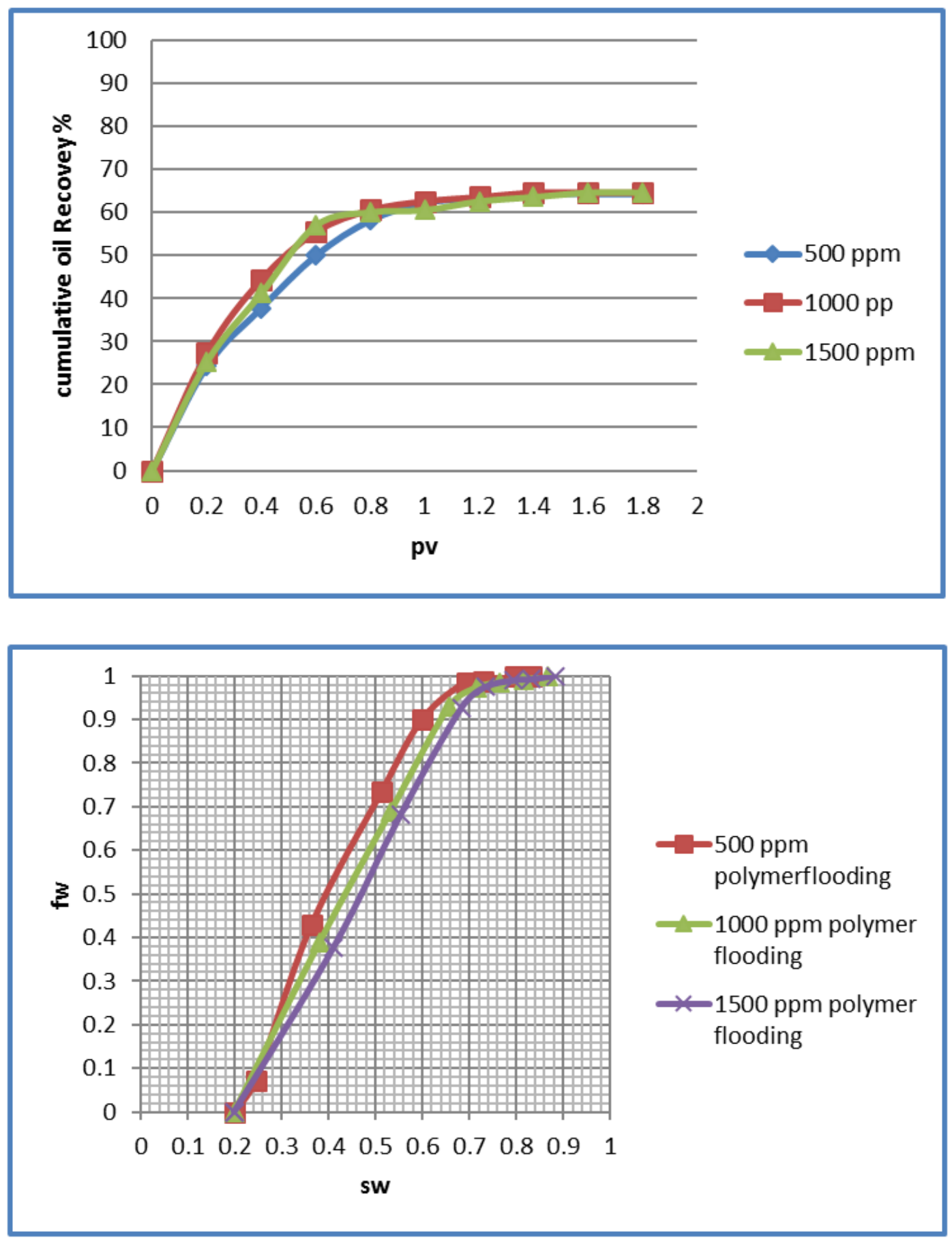